\title{
An unusual cause of an incidental lung mass
}

\author{
Lindsay M Lawson MDCM FRCPC ${ }^{1}$, Pari Tiwari $\mathrm{MB}^{2}$, J Douglas Filipenko MD FRCPC ${ }^{3}$
}

\begin{abstract}
LM Lawson, P Tiwari, JD Filipenko. An unusual cause of an incidental lung mass. Can Respir J 2003;10(5):276-277.

A 52-year-old woman was found to have a mass measuring $1 \mathrm{~cm}$ in diameter with radiographic features of a carcinoid tumour in the left lung during work-up for chest pain. Wedge excision of the lesion revealed a leiomyoma that had a similar histological appearance to uterine 'fibroids' removed eight years previously. This case is an example of benign metastasizing leiomyoma, an unusual lesion of uncertain etiopathogenesis.
\end{abstract}

\section{Une cause inhabituelle pour une masse pulmonaire d'importance secondaire}

\begin{abstract}
Une femme de 52 ans présentait une masse de $1 \mathrm{~cm}$ de diamètre avec des caractéristiques radiographiques d'une tumeur carcinoïde dans le poumon gauche lors d'un examen radiologique effectué pour vérifier une douleur pulmonaire. La résection cunéiforme de la lésion a révélé un léiomyome qui avait une apparence histologique semblable à une fibroïde utérine enlevée huit ans auparavant. Ce cas est un exemple de léiomyome métastasique bénin, une lésion inhabituelle d'une étiopathogenèse incertaine.
\end{abstract}

Key Words: Carcinoid; Leiomyoma; Lung mass

\section{CASE PRESENTATION}

A 52-year-old woman was discovered to have an abnormal chest radiograph during investigations for chest pain. The cause of the chest pain was a small myocardial infarction, subsequently treated with angioplasty and stent insertion. She had no respiratory symptoms.
The patient was exposed to tuberculosis as a child and was known to have a reactive tuberculin skin test of $15 \mathrm{~mm}$ induration. She had smoked one-half of a pack of cigarettes per day for approximately 10 years, quitting four years previously. Her travel history included visits to Las Vegas, Nevada, USA in the previous several years. Past medical history included allergic
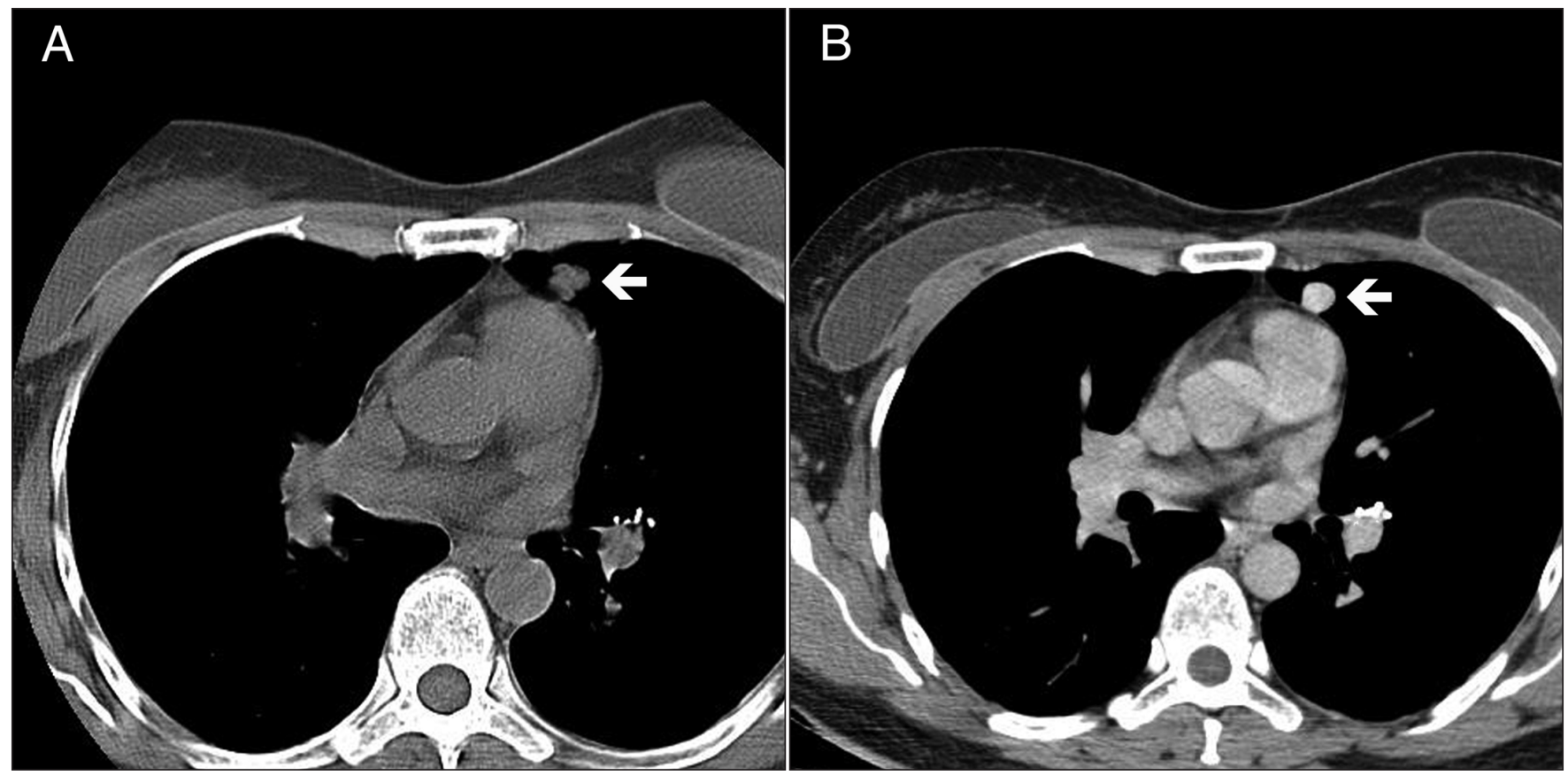

Figure 1) Computed tomography scan showing mass (arrow) in lingula (A) that showed radioenhancement after intravenous injection of contrast material (B)

${ }^{1}$ Division of Respiratory Medicine, Department of Medicine; ${ }^{2}$ Department of Radiology; ${ }^{3}$ Department of Pathology and Laboratory Medicine, St Paul's Hospital and the University of British Columbia, Vancouver, British Columbia

Correspondence: LM Lawson, Division of Respiratory Medicine, Department of Medicine, St Paul's Hospital and the University of

British Columbia, 490-1144 Burrard Street, Vancouver, British Columbia V6Z 2A5. Telephone 604-689-2768, fax 604-689-2895,

e-maillmlawson@shaw.ca 


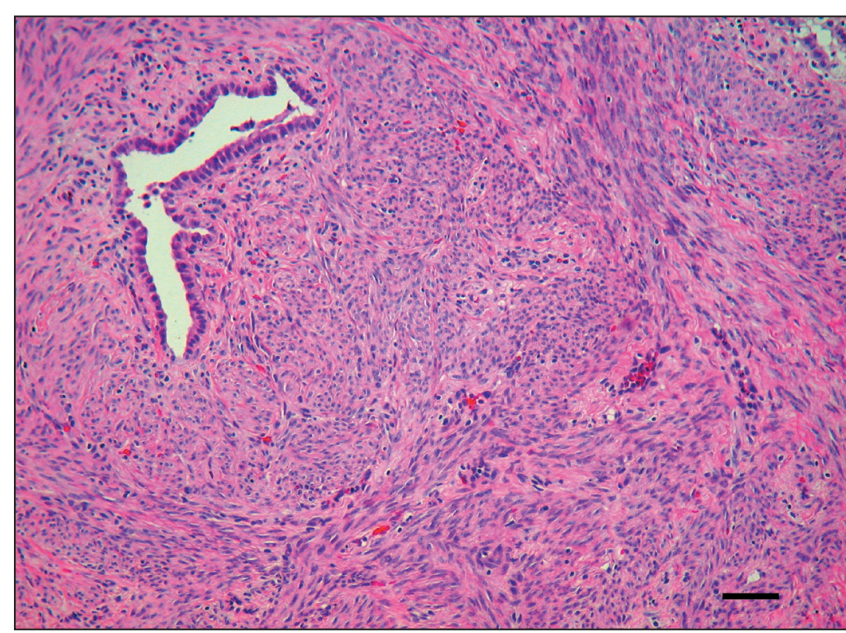

Figure 2) Photomicrograph of a wedge resection specimen of the left lung. Note the bundles of spindle-shaped cells with blunt-ended, 'cigarshaped' nuclei, characteristic of smooth muscle differentiation. (Hematoxylin and eosin stain; bar $=100 \mu \mathrm{m}$ )

rhinitis, hypercholesterolemia, a benign thyroid nodule and a hysterectomy eight years previously for uterine 'fibroids'. Her medications included enteric-coated acetylsalicylic acid, ramipril, atenolol, atorvastatin, premarin, mometasone furoate monohydrate (Nasonex, Schering, USA), and vitamin and mineral supplements.

Physical examination revealed a regular pulse of 60 beats/min and a blood pressure of $122 / 82 \mathrm{mmHg}$; the remainder of the physical examination was unremarkable. Results of routine blood work and pulmonary function tests were within normal limits. Chest $\mathrm{x}$-ray showed a well circumscribed, noncalcified nodule, $1 \mathrm{~cm}$ in diameter, in the midportion of the left lung. Computed tomography scan localized the lesion to the lingula, and the lesion showed enhanced radiodensity after injection of intravenous contrast material, consistent with a carcinoid tumour (Figure 1). There was no hilar or mediastinal lymphadenopathy, and the liver and adrenal glands had a normal radiographic appearance.

Histopathological examination of the surgically excised lesion (Figure 2) revealed that it had a similar appearance to the uterine leiomyoma removed eight years previously (Figure 3).

\section{DISCUSSION}

Benign metastasizing leiomyoma (BML) is a rare condition, characterized by the occurrence of one or more smooth muscle nodules, most often located in the lung, after previous hysterectomy for histologically benign-appearing leiomyoma.

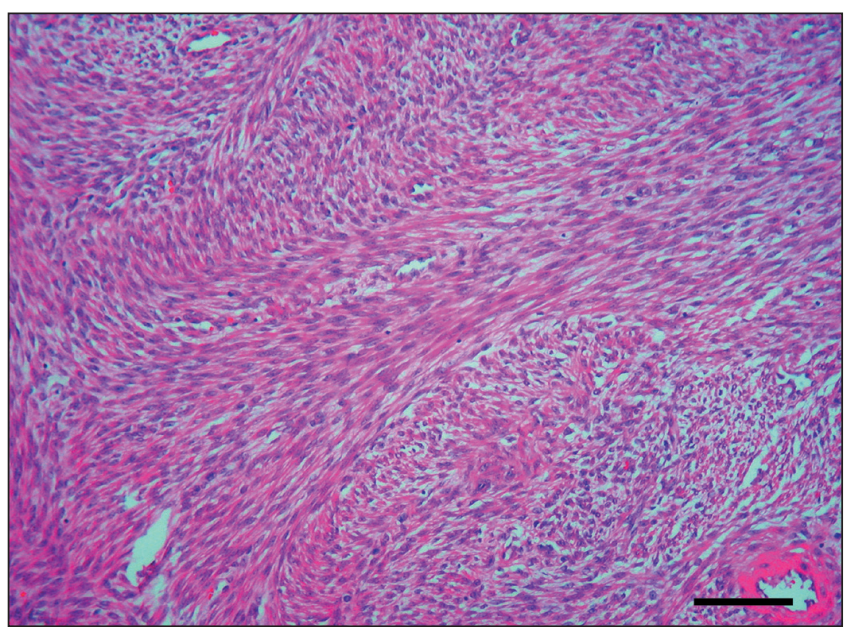

Figure 3) Photomicrograph of a section of uterine 'fibroid' from a hysterectomy performed eight years before the discovery of a pulmonary lesion. Note the similar histological appearance between the uterine leiomyoma and the lung lesion. (Hematoxylin and eosin stain; bar=100 $\mu \mathrm{m}$ )

There are two predominant theories regarding the origin of BML: metastasis from an existing leiomyoma; or multicentric leiomyomatous growths rather than actual metastases (1). In a recent study of a woman with BML, results of comparative genomic hybridization and $\mathrm{X}$ chromosome inactivation revealed monoclonality between the patient's uterine and pulmonary smooth muscle tumours, consistent with the pulmonary lesions being metastatic (2). BML can be considered a slow-growing variant of leiomyosarcoma of the uterus, which becomes clinically apparent at a young age and progresses slowly (3). Although it is biologically peculiar, BML should continue to be recognized as a distinct entity, because current histopathological criteria do not allow primary uterine smooth muscle tumours to be reclassified, even after documentation of pulmonary metastasis (4).

\section{REFERENCES}

1. Houck WV, Broderick TJ, Cohen SA, Cohen NM. Benign metastasizing leiomyoma. Surg Endosc 2002;16:716.

2. Tietze L, Gunther K, Horbe A, et al. Benign metastasizing leiomyoma: A cytogenetically balanced but clonal disease. Hum Pathol 2000;31:126-8

3. Kayser K, Zink S, Schneider T, et al. Benign metastasizing leiomyoma of the uterus: Documentation of clinical, immunohistochemical and lectin-histochemical data of ten cases. Virchows Arch 2000;437:284-92.

4. Esteban JM, Allen WM, Schaerf RH. Benign metastasizing leiomyoma of the uterus: Histologic and immunohistochemical characterization of primary and metastatic lesions. Arch Pathol Lab Med 1999;123:960-2. 


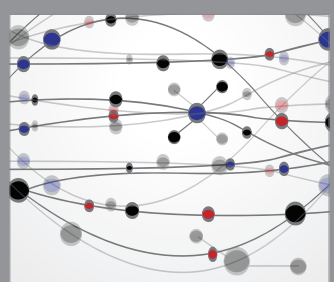

The Scientific World Journal
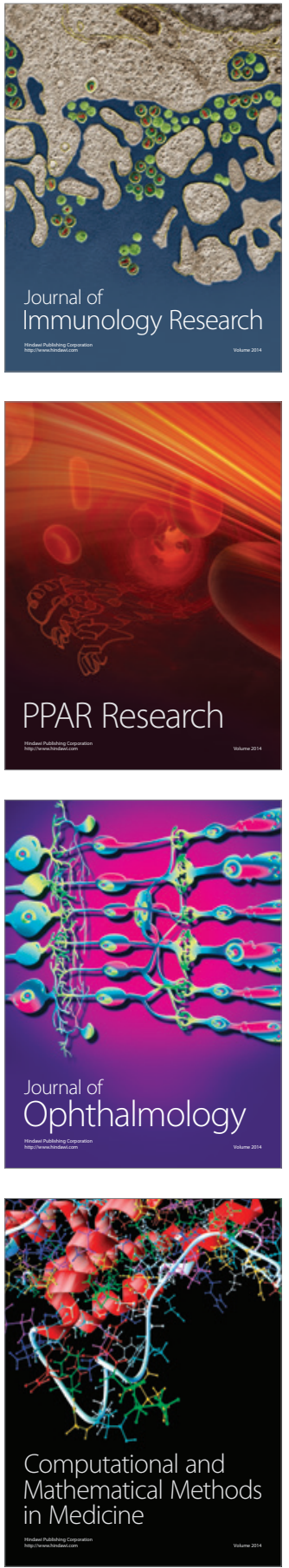

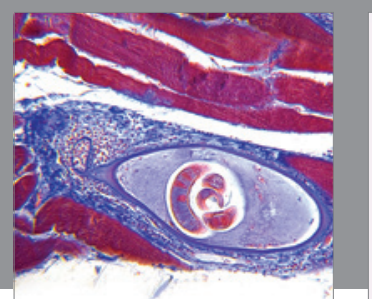

Gastroenterology Research and Practice

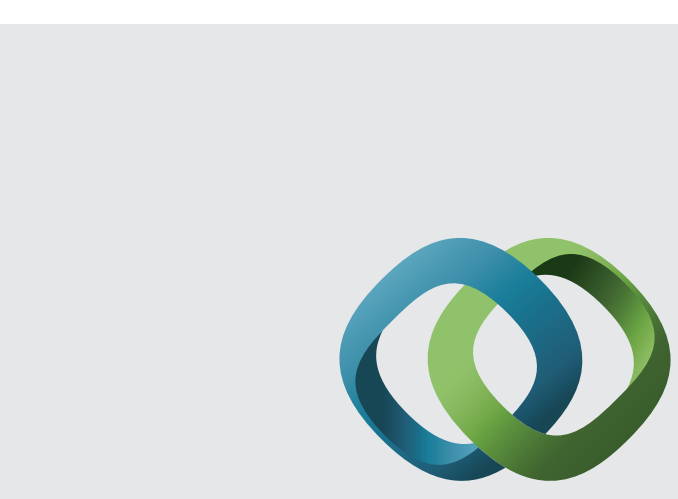

\section{Hindawi}

Submit your manuscripts at

http://www.hindawi.com
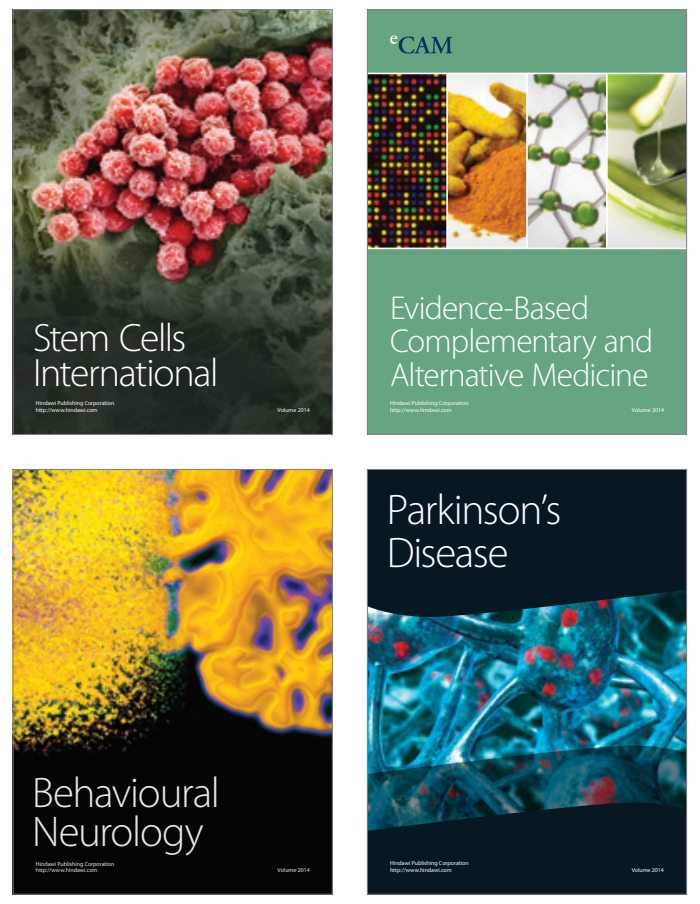
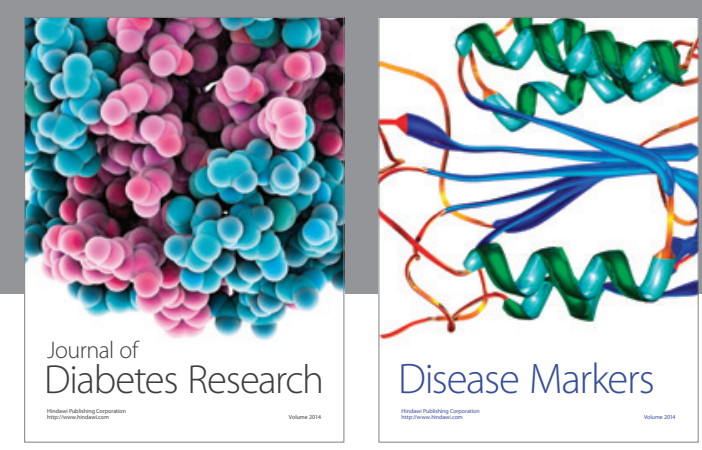

Disease Markers
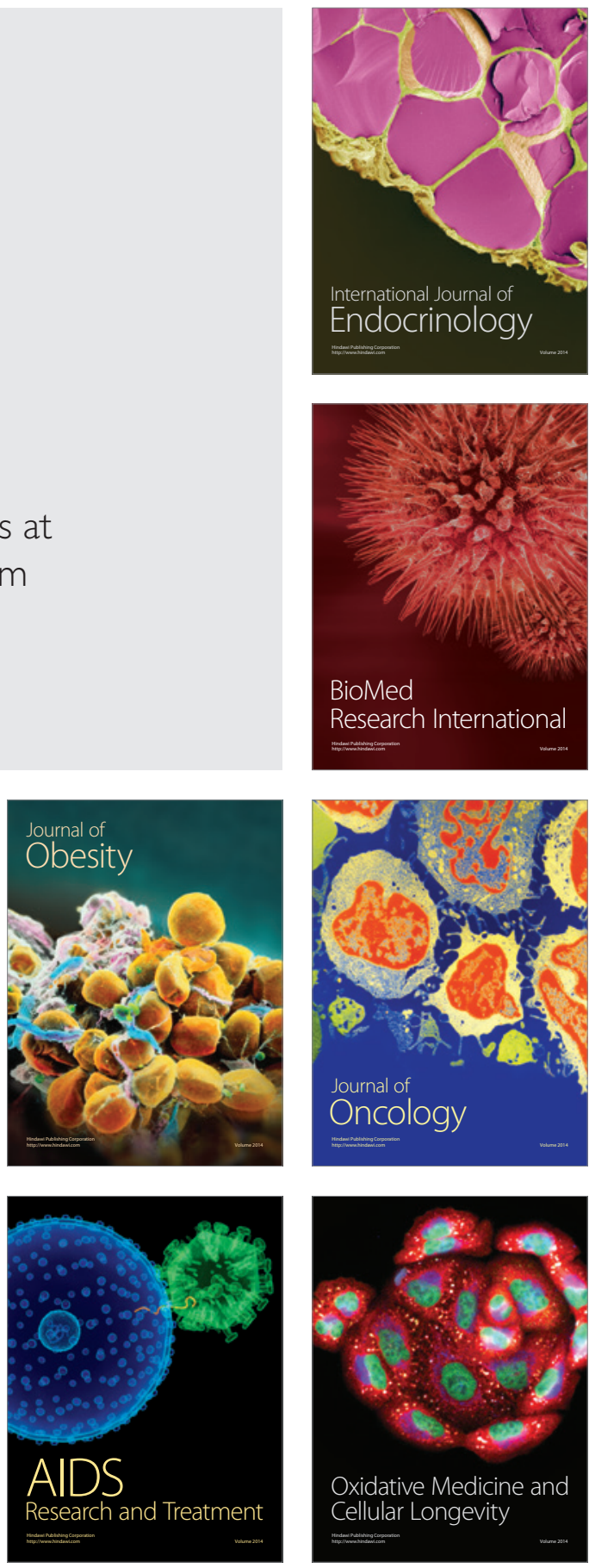